\title{
NOTES FROM THE SECRETARY
}

In the September number of the Chronicle members have been supplied with information regarding Canadian Forestry Association affairs, and particularly how these are related to this Society. Evente which have transpired since the writing of these notes are as follows:

In the October number of Forest and Outdoors there appeared the follow. ing notice of a special general meeting of members:

"The meeting of members of the Canadian Forestry Association called for Monday, October 9th, has been postponed until Monday, November 6th, and will be held at 306 Metcalfe St., Ottawa, at the hour of 2 p.m., for the purpose of considering and, if advisable, ratifying the action of the Board of Directors in changing the location of the Association's headquarters from the City of Ottawa, Ontario, to the City of Montreal, Quebec.

Ottawa, October 2, 1933."

ROBSON BLACK.

This meeting was held in the assembly room of the Boy Scouts Building, where the Forestry Association has its offices and different persons present have estimated the number in attendance at fifty. The meeting was attended by several members of this Society, but most of those present were non-technical members.

After some discussion regarding the use of proxies a motion was moved by Mr. A. C. Campbell, seconded by Henri Kieffer, ratifying the action of the Board of Directors in changing the location of the Association's headquarters from Ottawa to Montreal.

During the discussion of this motion both Dr. Howe and E. H. Finlayson were called to order by the President, as it was his ruling that a great deal of the subject matter in the statements of these men was irrelevant. This ruling was accepted by the speakers and was not disputed by the meeting.

After further discussion the motion was amended as follows: Moved by E. H. Finlayson, seconded by G. C. Piche:

"That the last two words of the said motion be deleted and that there be substituted therefore the following:

"That a committee consisting of John Bassett (Chairman) and Dr. C. D. Howe, J. A. Gillies, General J. B. White and G. C. Piche (members) be requested to consider and report as to whether or not it is advisable to approve of the resolution submitted to this meeting by the Directors that the chief place of business of the Association be moved from Ottawa to Montreal, in 
view of the fact that the resolution is contrary to the advice of a special committee previously appointed by the members to consider the matter, and especially in view of the charges made against the manager, which charges in the opinion of this meeting should also be thoroughly investigated by the said committee.

"And that, pending the report of the above committee any questions as to the further moving of the records or changes in personnel should be decided by the above committee and for the purpose of the said investigation all relevant records, papers, documents, vouchers and contracts should be available to the said committee.

"And that the said committee should also consider and report upon necessary reorganization of the Association's affairs, including headquarters, per. sonnel and finance;

"And that this meeting be now adjourned to the next annual meeting in January, 1934, before which date the report of the above committee should be ready for submission. Should any of the above members be unable or unwilling to act, he may nominate any other member of the directorate to act in his stead."

The amendment was passed with one dissenting vote and the motion as amended received the unanimous approval of the meeting.

On December 8th a meeting of the directors was held in Montreal with the following members present:

Messrs. Bassett (President), White, Howe, Campbell, Price, Ker, Ellwood Wilson, Sweezey, E. H. Finlayson, Piche, Reeder, Rossiter, Price-Green.

The important topic discussed at this meeting, as far as our members are concerned, was the resolution passed at the special members' meeting held in Ottawa on November 6th. After discussing this meeting, the following Minute was ordered to be entered on the records of the Association on motion of Mr. Sweezey, seconded by Mr. Ellwood Wilson. This was carried with three directors dissenting.

"The Board has met for the purpose of considering a resolution passed at a members' meeting at Ottawa on November 6th, 1933, which, in effect, demands that reconsideration be given to the acts of this Board in reducing the expense of the work of this Association;

"Whereas, after considerable discussion, the Board concluded that the Directors' decisions in the past have been for the permanent benefit of the Association;

"Therefore, be it resolved that these decisions be re-affirmed."

The following resolution was moved by General White, seconded by Mr. Arthur Campbell;

"That the Board re-affirms its confidence in the Manager." 
From the above, therefore, it will be seen that the Board of Directors of the Canadian Forestry Association has deliberately voted to ignore the members' meeting called by that Board and held at Ottawa on November the 6th.

Furthermore, information has been received that Mr. John Bassett, (Chairman) and General J. B. White, have refused to act on the committee appointed by the Ottawa meeting and also have refused to name a substitute.

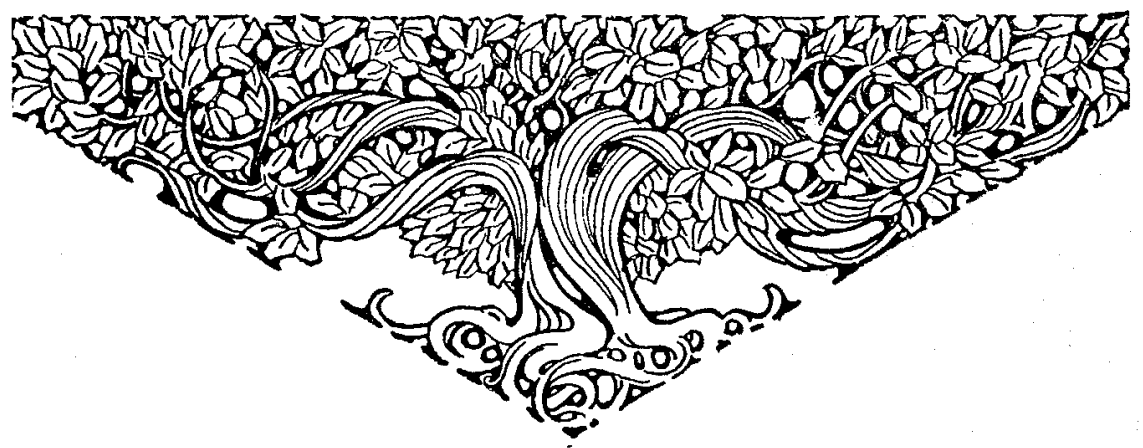

